\title{
AN EFFECTIVE METHOD FOR COLLECTING ECTO- PARASITES FROM LIVE ANIMALS AND BIRDS
}

\section{By LaWRence H. DUNN}

Medical Entomologist and Assistant Director, The Gorgas Memorial Laboratory, Panama, R. de P.

The following method for collecting ectoparasites from live animals and birds that has now been used for some time by the writer has proved to be very effective and it is believed that a published description of it may be of interest to parasitologists, entomologists and others that are sometimes engaged in collecting ectoparasites.

This method was first tried out in securing specimens of fleas from a young peccary, or wild pig, Pecari angulatus bangsi Goldman. This animal, which apparently was between two and three months of age and weighed about seven pounds, had recently been captured by men engaged in the construction of a new road in the Canal Zone. Through the kindness of Mr. Louis Hulcher, Foreman on the road work, the peccary was brought to this laboratory in order that it might be examined for blood parasites and also to provide an opportunity for collecting specimens of the fleas with which it was heavily infested.

This animal had been quite gentle and was kept as a pet at the camp of the road builders where it had lived for a number of days. On arrival at the laboratory it seemed to be frightened by the strange surroundings and strongly resisted being handled. The vigorous struggles of the pig and the activity of the fleas formed a combination which made the capture of many specimens rather a difficult task. It was evident that unless some method was devised for collecting the fleas, other than by using fingers or forceps or inverting glass tubes over them, our catch was not likely to be a very large one. In view of this, the following procedure was tried out. A narrow strip of adhesive tape wound several times around the snout and under the lower jaw of the pig acted as a muzzle and effectually pre- 
vented it from biting. The forefeet were tightly fastened together with a piece of one-inch bandage and after the hind feet had been secured in like manner a short strip of the bandage was used to connect the fore and hind feet. This strip was about eight inches in length and prevented the forefeet from being separated from the hind feet for a distance of more than its length. This permitted some movements of the legs but prevented the animal from using them too freely. The pig was then placed in a sitting position in a large glass anatomical jar with its head above the top of the jar and a towel placed about its neck somewhat after the manner in which a barber's apron is used. This left one side of the towel wrapped tightly about the neck of the pig while the other part was spread out to completely cover the top of the jar. An elastic band stretched around the top of the jar and the outer edge of the towel served to hold the latter closely in place. As the animal rested on its hind feet the bandage connecting them with the forefeet held the latter down in the jar and prevented them from being hooked over the top of the jar or to claw at the towel. One hand grasping the towel at the nape of the neck of the pig sufficed to hold the animal upright with its head above the top of the jar as well as to keep the towel tightly in place about its neck. Chloroform was then liberally sprinkled about on the towel in rather close proximity to the pig's neck but not near enough to permit the liquid to reach the animal's body. The vapor of the chloroform being heavier than air readily penetrated through the towel to the bottom of the jar. The effect of the chloroform vapor on the fleas quickly became evident and in less than a minute many of them were seen leaving the pig and falling to the bottom of the jar. A few that came up on the head of the animal were stupefied and were collected by dabbing them with a small pledget of cotton wet with chloroform. In about four minutes the pig was taken from the jar and after removing the towel from about its neck the animal was given a brief combing to remove the few dead or stupefied fleas that were adherent to the hair or skin. A careful examination of the animal 
was then made and it seemed to be entirely free from the fleas.

It was very easy to collect the dead and stupefied fleas from the bottom of the jar. Inverting the jar over a piece of white paper caused the greater number of them to fall on the paper from which they were transferred to tubes of alcohol. The few that remained sticking to the inside of the jar were easily picked up on the side of a dissecting needle wet with alcohol.

A total of 148 fleas were collected from the peccary at this time and although the animal was kept at the laboratory for several weeks and was examined at frequent intervals no more fleas were ever found on it.

A short time later there was an occasion to examine a number of marmosets, or squirrel monkeys, Leontocebus geoffroyi (Pucheran), for possible ectoparasites before placing them in the animal house at this laboratory. These animals had been recently captured and being vicious biters were difficult to handle in so far as examining them closely for ectoparasites was concerned. Since they were hardly larger than a squirrel and it was necessary to hold them tightly in gloved hands in order to prevent biting, there was but little of an animal's body left exposed for examination. By using the chloroform-jar-method the examination of these monkeys was simplified to a great extent and it was quite surprising to find so many of them infested with fleas. Although the short snout of this species of monkey precluded using adhesive tape as a muzzle the towel and skin when held together at the nape of the neck prevented them from turning to bite or moving to any great extent. When this method is used on animals having prehensile tails, such as monkeys, opossums, etc., the tail is usually fastened to the hind feet in order to keep it away from the top of the jar.

A black spider monkey, Ateles dariensis Goldman, that was found to be heavily infested with lice was treated with this chloroform vapor method and Pediculus to an estimated number of from 4000 to 6000 were obtained.

Numerous opossums, Didelphis marsupialis etensis Al- 
len, have been cleared of fleas with this method and it was also found to be very successful when tried out on Coatis, Nasua narica panamensis Allen, and grisons, Grison canaster (Nelson), many fleas and lice being obtained from these animals.

When treating animals that have long thick hair or fur after taking them from the jar it is necessary to rub the hair briskly with the fingers or use a comb in order to remove the inert fleas or lice that remain clinging to the hairs.

This method is easily applied to birds and has proved to be very effective in clearing them of lice. The wings are brought up over the back and fastened together with two or three turns of a narrow bandage that is drawn up between the feathers close to the wing. The feet are tied together with a piece of string or with a rubber band or they may be left free to allow the vapor more freely to reach the area between the thighs. After removing the bird from the jar it is held over a large piece of white paper and its feathers vigorously ruffled and drawn upward with the fingers to cause the stupefied lice to fall clear of the feathers. A tinamou, Tinamus major castaneiceps Salvadori, when treated in this way recently yielded 603 lice, representing three genera, Conoides, Ornicholax and Kelloggia. A total of 176 lice, 122 Columbicola and 54 Goniocotes, were obtained from a domestic pigeon.

This method is now being used as a routine measure on all animals and birds received at this laboratory. The ease with which abundant yields of ectoparasites are obtained by its use leads me to believe that it may be extremely useful if used on a larger scale in clearing domestic fowls, dogs, etc., of fleas, lice and mites. Investigations on its application along more practical lines will be carried out in the future.

The specimens of ectoparasites are in good condition and in much better shape to be studied when collected by this method and are seldom found partly crushed or with many spines or hairs broken off as so frequently occurs when collected with forceps or fingers. 

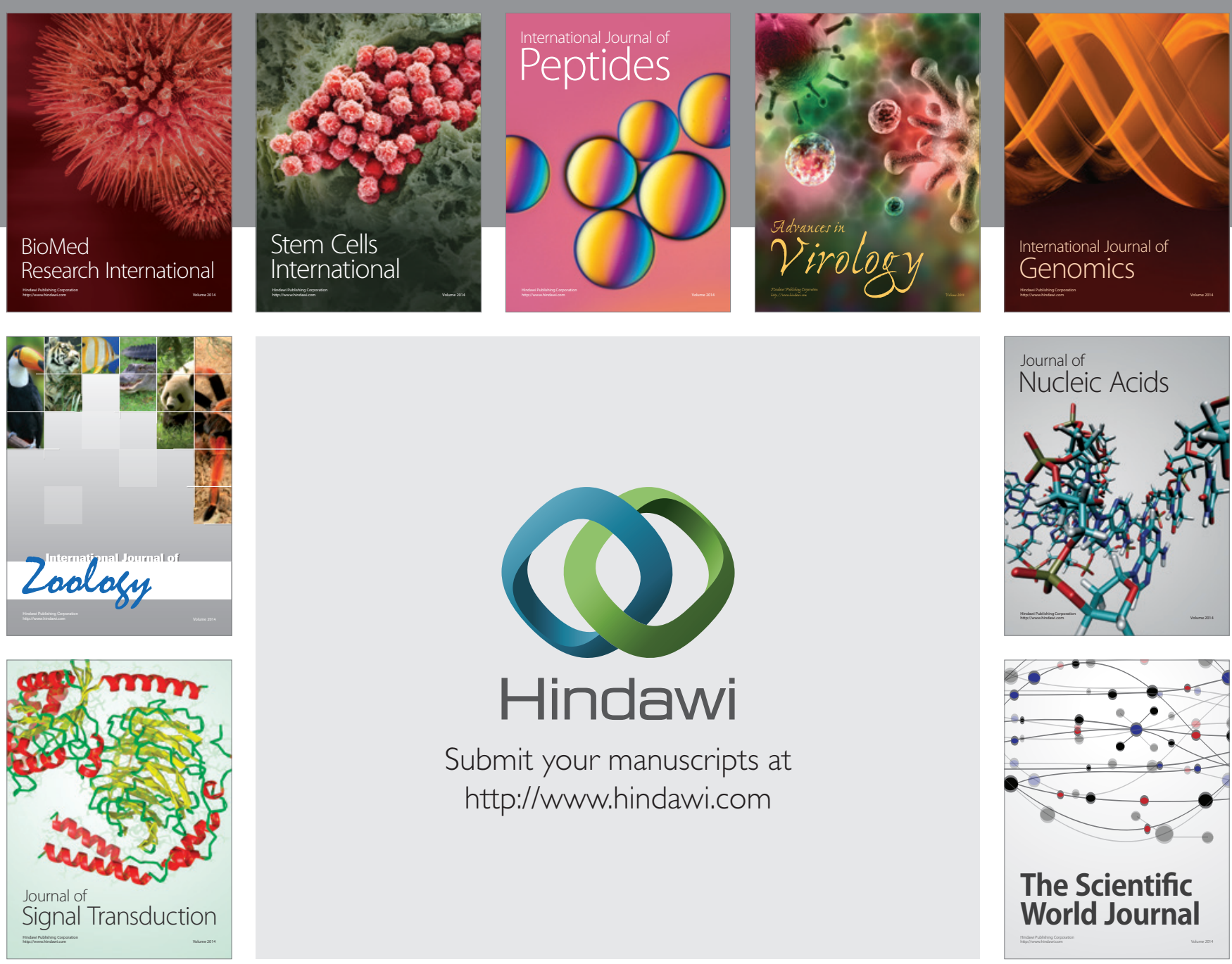

Submit your manuscripts at

http://www.hindawi.com
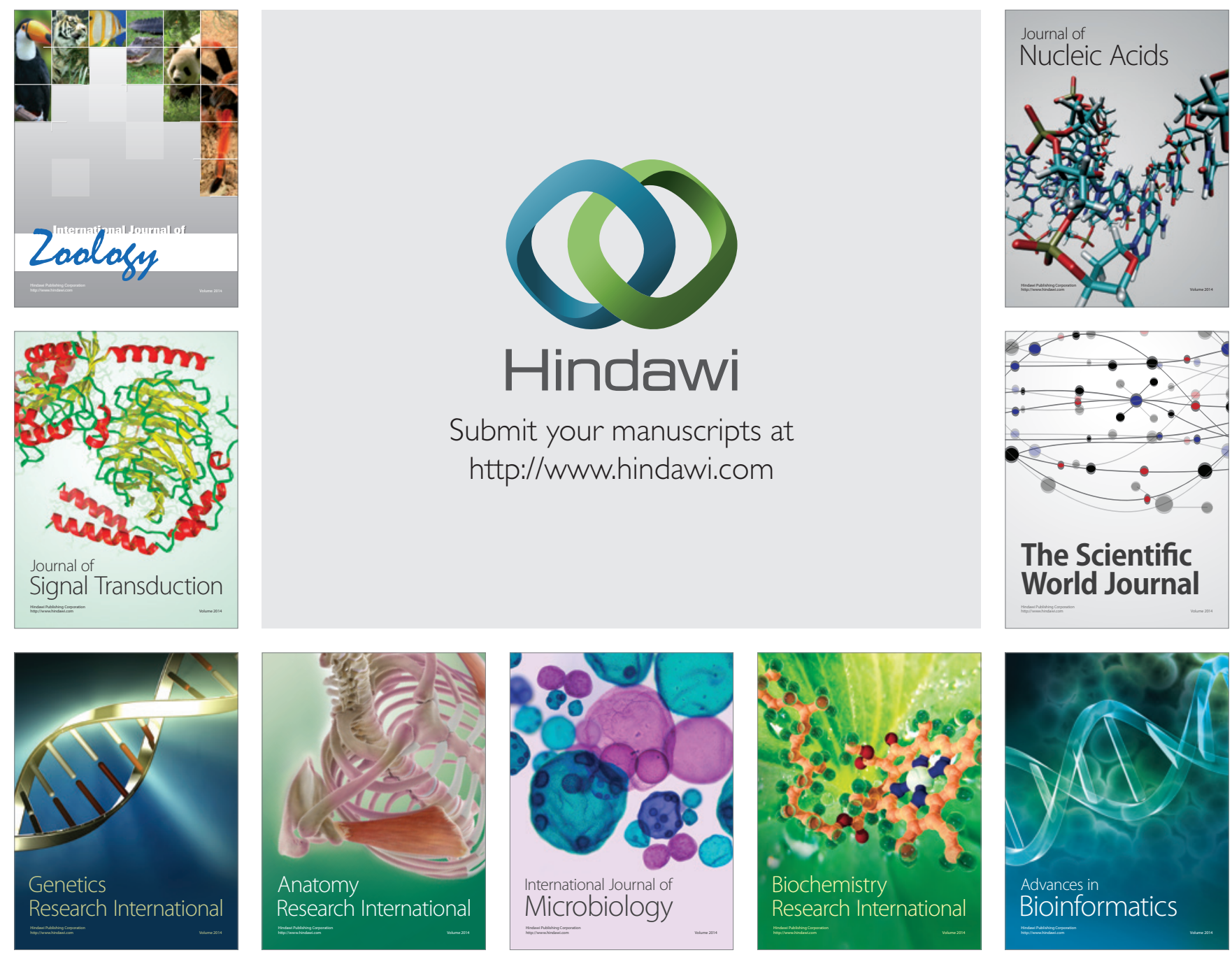

The Scientific World Journal
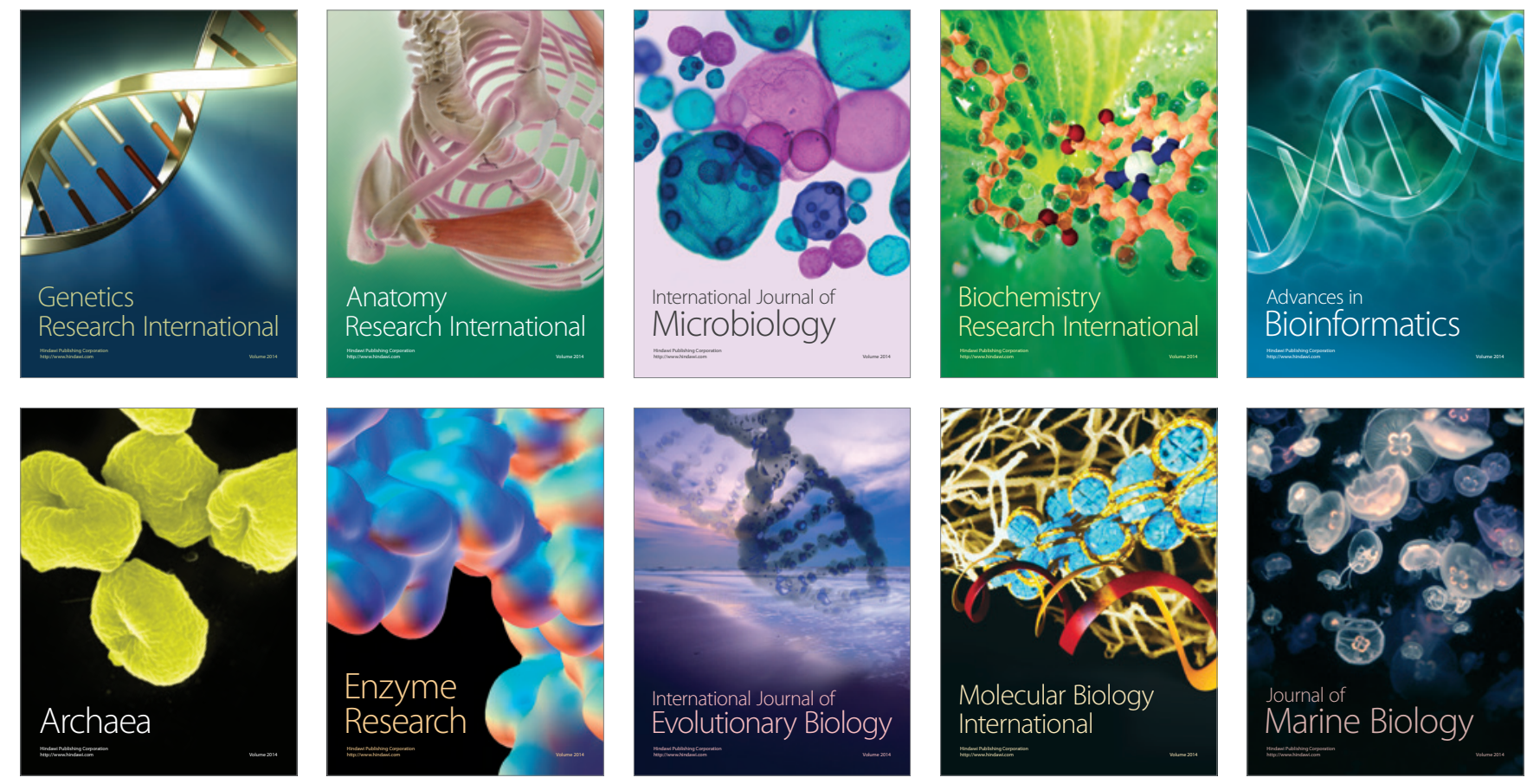